\title{
Mineral Oil and Ester Based Oil/Paper Insulation Decaying Assessment by FTIR Measurements
}

\author{
U. Mohan Rao ${ }^{1}$, I. Fofana ${ }^{1}$, R. Kartheek ${ }^{2}$, K. M. L. Yapi ${ }^{1}$, and T. Jaya ${ }^{1}$ \\ ${ }^{1}$ Research Chair on the Aging of Power Network Infrastructure (ViAHT), \\ University of Quebec at Chicoutimi, Chicoutimi, QC G7H 2B1, Canada. \\ ${ }^{2}$ University Center for Aluminum Research (CURAL), \\ University of Quebec at Chicoutimi, Chicoutimi, QC G7H 2B1, Canada. \\ ifofana@uqac.ca
}

\begin{abstract}
Esters based dielectric fluids have been widely researched since 1990's for application in high voltage insulation applications. Since then, researchers are affirmative towards usage of ester based insulating fluids as a replicated to mineral insulation oils. The operating properties and aging performance of ester oils proved to be potential candidates for high voltage applications. In view of high temperatures and longevity of insulation systems, there also is a need to understand the chemical perspectives along with aging behaviour of ester oils. Accelerated aging of oil/paper insulation associated with mineral oil and synthetic ester with cellulose insulant has been experimentally simulated as per ASTM D 1934 at $115^{\circ} \mathrm{C}$. Fourier Transform Infrared spectroscopy analysis of oils and cellulose papers is carried out at different aging factors. The compositional changes in oils and cellulose kraft paper with aging have been enumerated. The changes in the absorbance area for appropriate functional groups have been also reported. It is found that, the chemical stability of synthetic esters is superior to that of the mineral oil.
\end{abstract}

Keywords: Transformers, Insulation, Ester oils, FTIR Spectroscopy.

\section{$1 \quad$ Introduction}

Since years, mineral insulating oils are been successfully used in transformer technology for insulation and cooling purposes. However, with experience, engineers realized the requirements of high dielectric and thermal performance of the insulating fluids. Consequently, mineral oil (MO) is facing some serious critiques in terms of fire point resources and biodegradability. Global research on alternative insulating fluids is affirmative towards usage of ester based dielectric fluids as a replicate to mineral ones [1]. Studies revealed that, synthetic ester (SE) is a suitable candidate for use in breather transformers and natural ester (NE) performs well in sealed transformers [2-4].

Performance of insulating oil degrade with operating times and is required to monitor periodically to ensure oil pristine conditions. Hence, there are several parameters associated with oil that are to be maintained in proper limits [5]. Dielectric and physi- 
ochemical parameters of synthetic esters and natural esters have been widely investigated and is established that, ester based fluids are superior to mineral oils [ref]. Insulating oil is used in conjunction with insulation paper and hence the compatibility of new insulating oils with paper is to be ensured. Researchers have investigated the performance of insulation paper in various insulating oils and reported the reduced degradation of cellulose papers in new oils $[6,7]$.

The change in the quality of oil in transformer may be attributable to several reasons including electrical stress, thermal stress, and oil/paper interface properties. It is to be noticed that, these attributes involves in changing the chemical state of the oil/paper insulation. This is because, aging of oil involves in formation of aging products like acids, dissolved decay contents, dissolved gases, polar solvents and sludge which hinders the performance of insulation system. Aging of paper is also evident with production of some chemicals like furfurals, methanol, and acids. The degradation aspects of oil/paper insulation is involved with several chemical changes. Thus, there is a need to study the changes in chemical compositions that occur with aging of oil/paper insulation. Fourier Transform Infrared spectroscopy (FTIR) analysis of oil/paper insulation based on mineral oil and cellulose insulant have been reported in $[8,9]$. Also, chemical compositional changes for natural ester and cellulose based insulation have been reported by researchers [10]. Comparative FTIR analysis of mineral oil, natural ester, and synthetic ester is also reported by researchers [11].

In this paper, FTIR analysis of oil/paper insulation associated with mineral oil and synthetic ester have been reported for different aging factors. FTIR analysis of mineral oil, synthetic ester, and kraft paper (aged in MO and SE) have been reported. It is noticed that, surface interaction of synthetic ester with cellulose kraft showed a significant stability in its chemical structure as compared to that of the mineral oil.

\section{Experimental}

Initially, mineral oil, synthetic ester, and cellulose kraft paper were subjected to drying in order to remove moisture. Dry oils and papers are transferred to aging cells and are later subjected to thermal aging as per ASTM D 1934. Oil/paper ratio adopted is $10: 1$, which is universally followed for oil/papers insulation studies for transformers. Thermal aging followed $500,1000,1500$, and 2000 hours of test durations at $115^{\circ} \mathrm{C}$. After every test duration, FTIR characterization is carried out for insulation oils. Simultaneously, cellulose kraft papers aged in mineral oil and synthetic ester are subjected to degreasing in hexane fumes for one hour to remove the traces of oil absorbed by cellulose fibres. Later, aged and degreased cellulose kraft papers are also subjected to FTIR characterization. In order to establish the base line prior to aging, fresh mineral oil, fresh synthetic ester and unused cellulose kraft paper are also subjected to FTIR. The peaks obtained during FTIR characterizations are compared and analysed to comment on the compositional changes with aging. 


\section{Results and Discussion}

To understand the changes in chemical composition of oil/paper insulation with aging, different aging factors have been simulated under laboratory conditions. The changes in the surface functional groups are monitored by FTIR.

\subsection{FTIR Spectrum of Mineral oil}

FTIR spectra of fresh and aged MO at various aging factors is presented in Fig. 1.

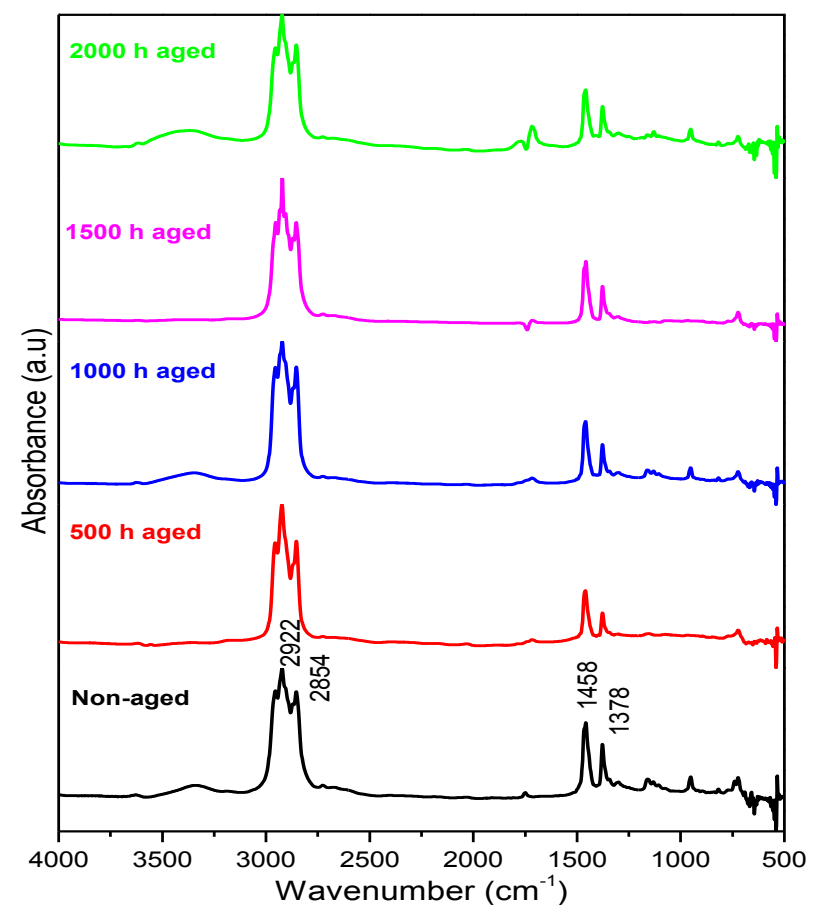

Fig. 1. FTIR spectra of fresh and aged MO

Broad O-H stretching vibration is observed in the fresh and aged samples. However, intensity profile of O-H peaks is noticed to be low. Fig. 2(a) shows the high frequency FTIR regions for peak positions of 2922 and $2854 \mathrm{~cm}^{-1}$. These peaks are attributed to $-\mathrm{CH}_{2}$ vibrations accompanied by a small peak at $2954 \mathrm{~cm}-1$ that is related to $-\mathrm{CH}_{3}$ vibrations [9]. The polar type of hydrocarbon bonds are the internal chemical signatures of MO. The degradation performance of $\mathrm{MO}$ is studied by observing the peak area under $\mathrm{CH}$ bonds for different aging conditions as shown in Fig. 2(b). The hydrocarbon group from the $2000 \mathrm{~h} \mathrm{MO}$ showed decrease in the $\mathrm{CH}$ bond peak area compared to the fresh MO. 


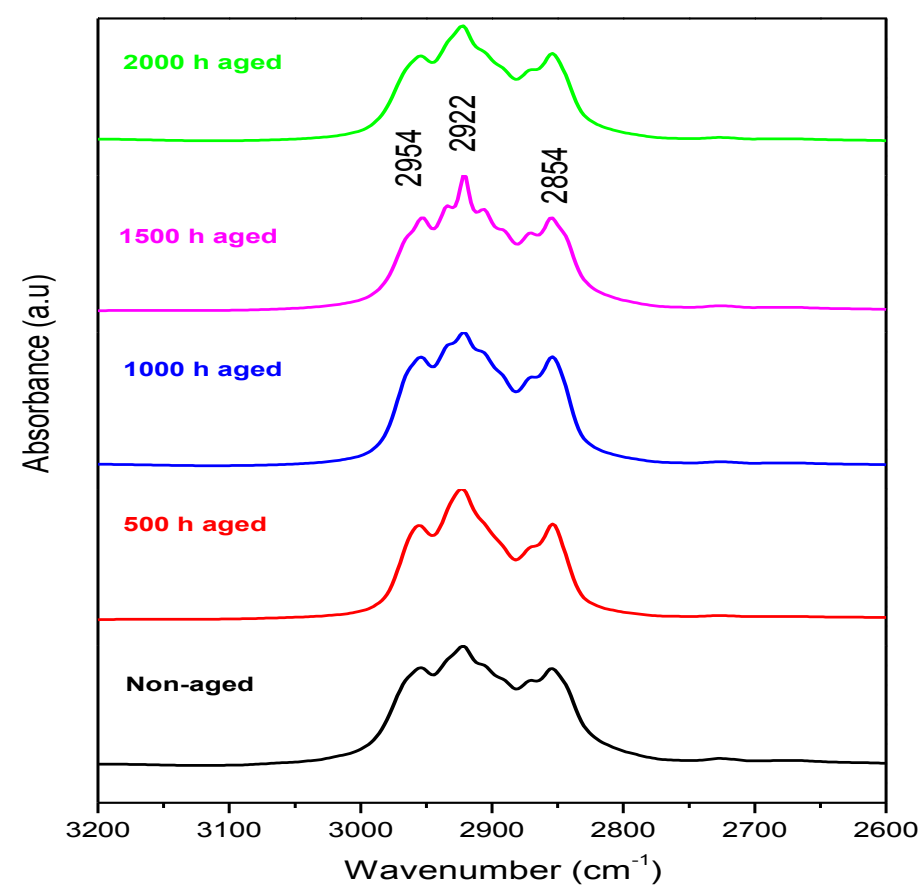

(a)

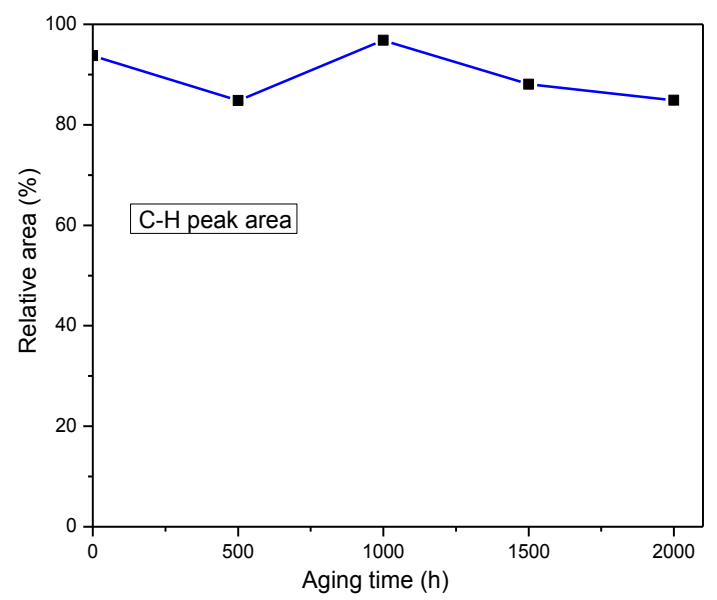

(b)

Fig 2. (a) Mineral oil peak positions at 2954,2922 and $2854 \mathrm{~cm}^{-1}$ (b) the corresponding area quantifications

FTIR spectrum of peak positions for 1458 and $1378 \mathrm{~cm}^{-1}$ are presented in Fig. 3. The peak positions are attributed to $-\mathrm{CH}_{2}$ bending vibrations that result in the similar trend as the main $-\mathrm{CH}_{2}$ and $-\mathrm{CH}_{3}$ vibrations. 


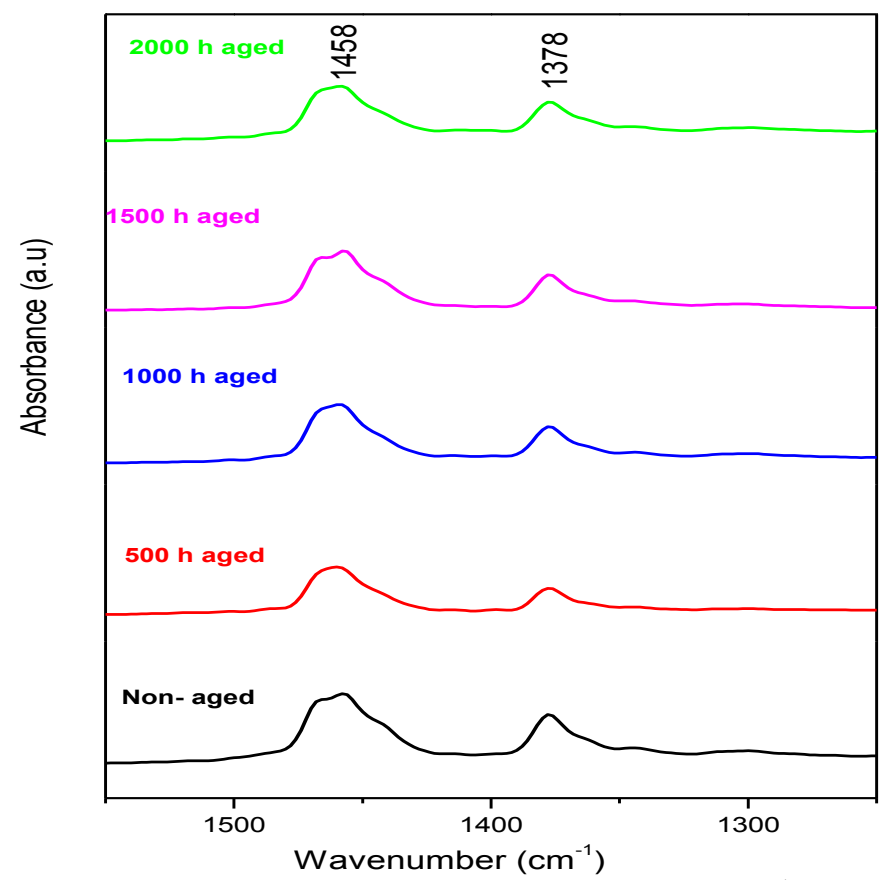

Fig. 3. Mineral oil peak positions of 1458 and $1378 \mathrm{~cm}^{-1}$.

\subsection{FTIR Spectrum of Synthetic Ester}

FTIR spectra of fresh and aged synthetic ester at 500, 1000, 1500 and 2000 hours are presented in Fig. 4.

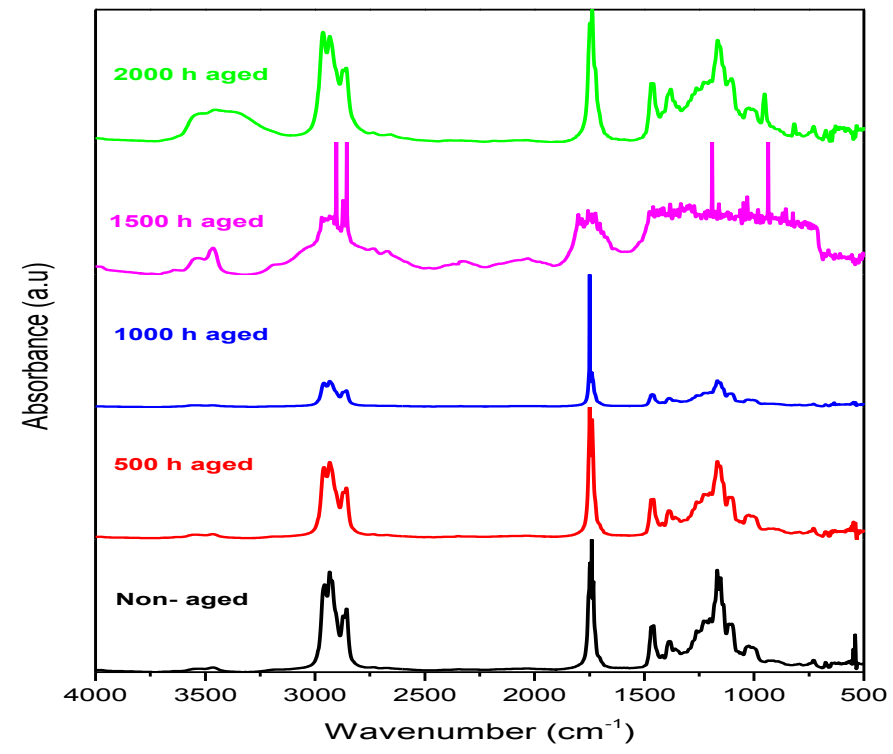

Fig. 4. FTIR spectra of SE at different aging conditions 
The chemical signature of synthetic ester resulting as $\mathrm{CH}_{2}$ and $\mathrm{CH}_{3}$ vibrations are noticed at the peak positions of 2854 and $2922 \mathrm{~cm}^{-1}$ respectively. In addition, $\mathrm{C}=\mathrm{O}$ peaks positions are also observed in all the samples at $1750 \mathrm{~cm}^{-1}$. To understand the influence of surface oxidation on synthetic ester, hydroxyl peak $(\mathrm{OH})$ at 3200-3500 $\mathrm{cm}^{-1}$ is quantified and the relative area is shown in Figure 5. The relative increase in the intensity of $\mathrm{OH}$ vibrations at higher aging times is related to surface oxidation of its chemical structure (see Fig. 5(b)) [11]. Similarly, ester's signature peak of carboxyl group for aging factors and corresponding relative area is plotted in Fig. 6.

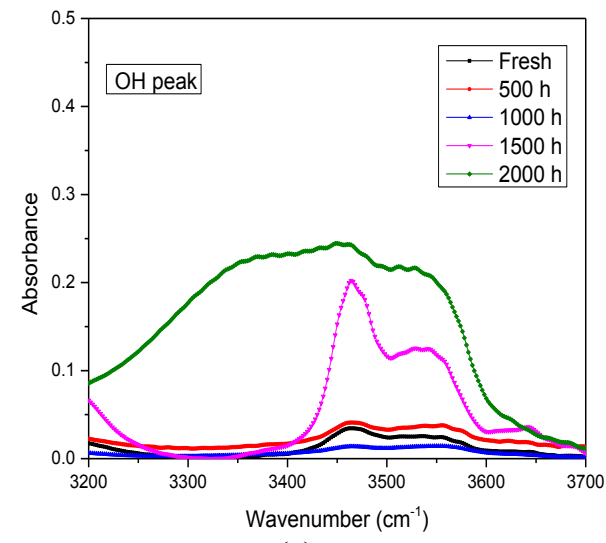

(a)

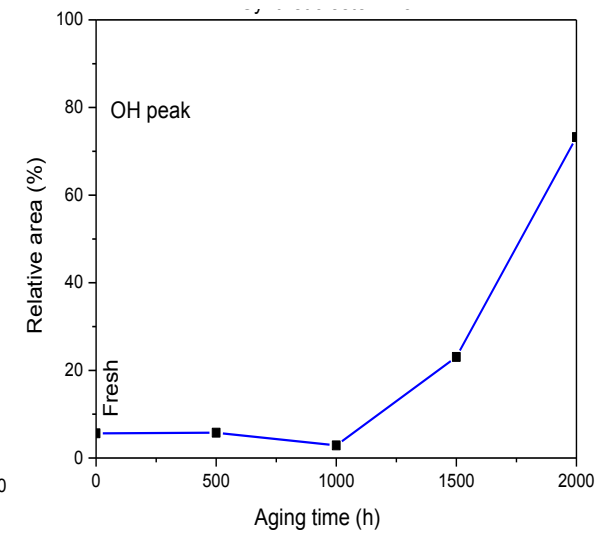

(b)

Fig. 5. (a) FTIR peak position at $3200-3500 \mathrm{~cm}^{-1}$ and its (b) corresponding peak area (SE)

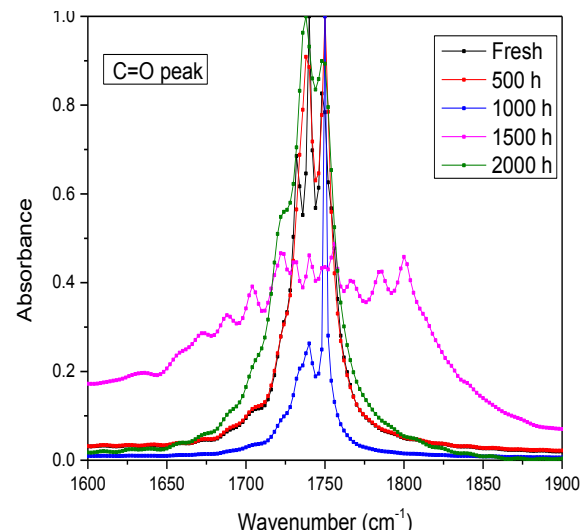

(a)

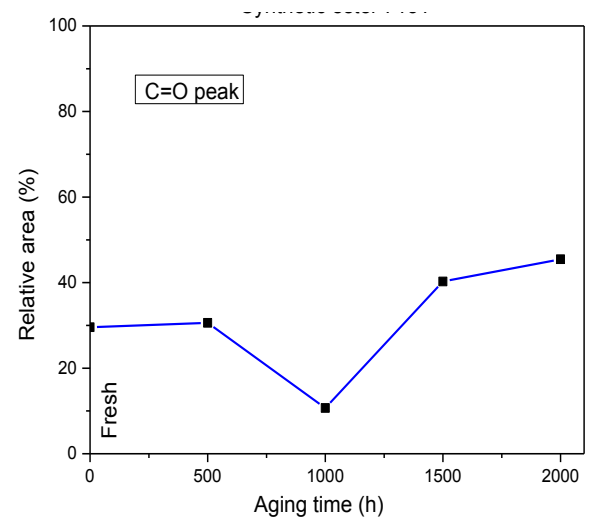

(b)

Fig. 6. (a) FTIR peak position at $1750 \mathrm{~cm}^{-1}$ and its (b) corresponding peak area (SE)

The relative area associated with $\mathrm{C}=\mathrm{O}$ peaks is observed to increase with aging of insulation. However, the percentage relative area at different aging factors at 1500 and $2000 \mathrm{~h}$ resulted in a small change as compared to fresh SE. 


\subsection{FTIR Spectrum of Cellulose Kraft Paper Aged in MO and SE}

Further, to understand the properties of oil/paper interactions and their changes in the chemical structure. Aging of MO and SE is carried out in presence of cellulose. Kraft paper is degreased in hexane fumes to remove the traces of oil absorbed by cellulose fibres. Degreasing is done in order to observe the chemical compositional changes that occur in the insulation paper with aging of oil/paper insulation. The FTIR peaks of degreased kraft paper aged in mineral oil at different aging factors is presented at Fig. 7.

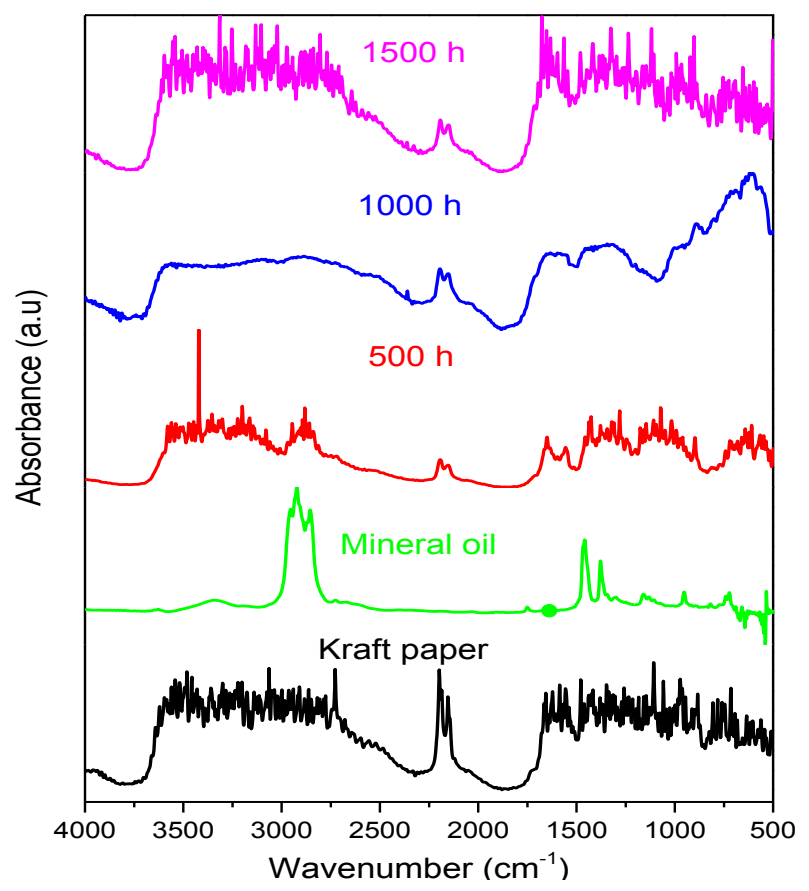

Fig. 7. FTIR spectra of cellulose Kraft paper aged in Mineral oil

Fresh and dehydrated kraft paper showed the broad range of signature at the hydroxyl group from 3500 to $3000 \mathrm{~cm}^{-1}$. This is the result of atmospheric $\mathrm{OH}$ interaction with the chemical structure of cellulose. Apart from this, the strong absorbance peak at $2200 \mathrm{~cm}^{-1}$ is a result of $\mathrm{C} \equiv \mathrm{C}$ functional group from the cellulose structure. In fingerprint region, below $1500 \mathrm{~cm}^{-1}$, very less information observed. In comparison to the fresh kraft paper, kraft paper aged in MO shows a distinct feature at around 1700 $\mathrm{cm}^{-1}$. This is attributed to the $\mathrm{C}=\mathrm{O}$ vibrations as a result of oil interaction with cellulose during aging [10]. To understand the decomposition of $\mathrm{C} \equiv \mathrm{C}$ functional group, aged samples of $2200 \mathrm{~cm}^{-1}$ is plotted as shown in Fig. 8 . 


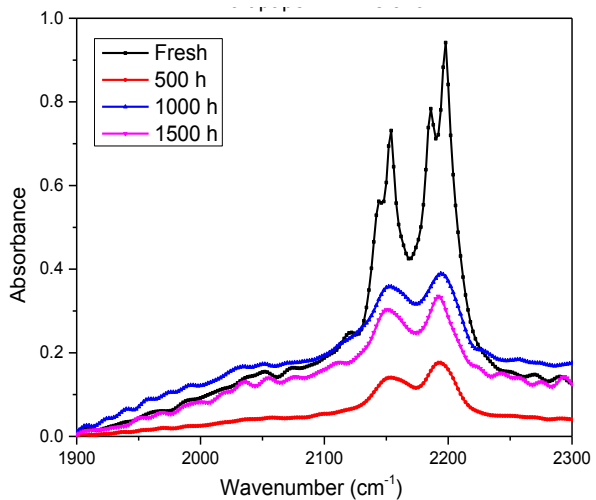

(a)

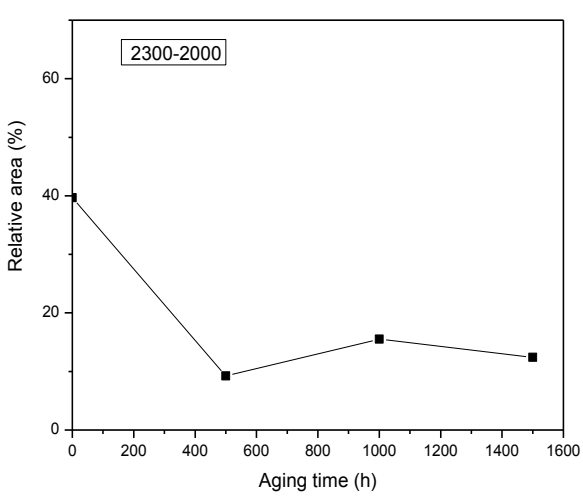

(b)

Fig. 8. (a) FTIR peak position at $2200 \mathrm{~cm}^{-1}$ and (b) the corresponding relative peak area of cellulose paper aged in $\mathrm{MO}$

There are two distinct signatures observed at 2150 and $2200 \mathrm{~cm}^{-1}$ which is ascribed to alkynes of $\mathrm{C} \equiv \mathrm{C}$. The calculated relative peak area indicate a significant decrease in quantity of $\mathrm{C} \equiv \mathrm{C}$ for aged samples. This correspond well with the appearance of new peak of $\mathrm{C}=\mathrm{O}$ at $1700 \mathrm{~cm}^{-1}$. FTIR spectra of degreased kraft paper aged synthetic ester in illustrated in Fig. 9.

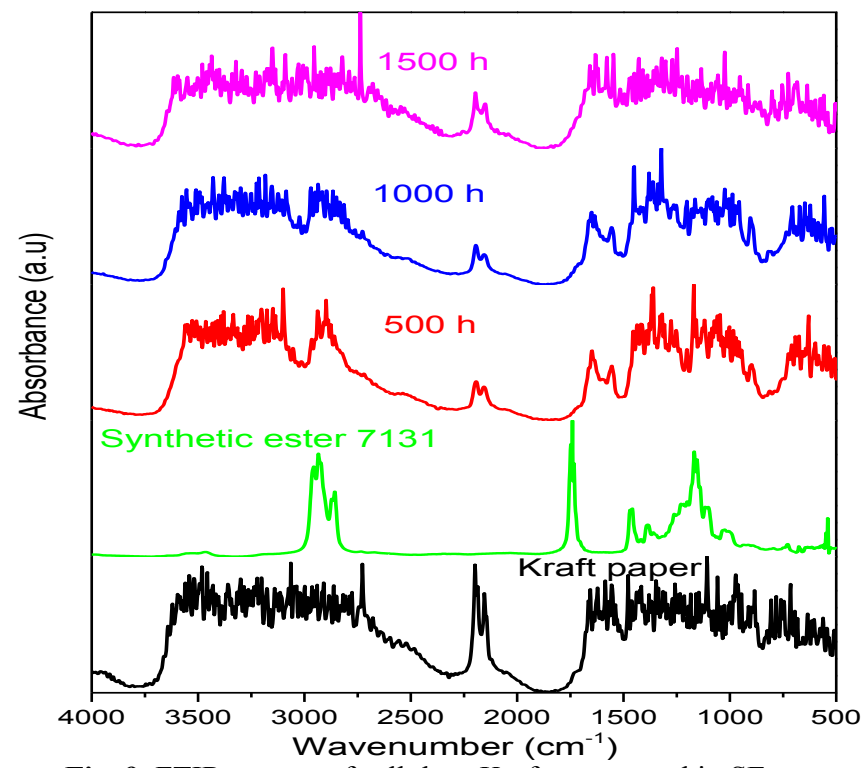

Fig. 9. FTIR spectra of cellulose Kraft paper aged in SE

Distinctive signature of cellulose $\mathrm{C} \equiv \mathrm{C}$ functional group is observed for kraft paper aged in SE. However, the intensity of $\mathrm{C} \equiv \mathrm{C}$ vibrations decreased due to the surface coverage of synthetic ester on the cellulose chemical structure. In addition, the signatures of $-\mathrm{CH}_{2}$ and $\mathrm{CH}_{3}$ vibrations are clearly observed along with the cellulose structure at 2854 and $2954 \mathrm{~cm}^{-1}$. The $\mathrm{C}=\mathrm{O}$ signa- 
ture at $1700 \mathrm{~cm}^{-1}$ on ester internal chemical structure has a shift when it reacted with cellulose on aged samples. However, the shift was observed at $1650 \mathrm{~cm}^{-1}$ along with the new peak appeared at $1550 \mathrm{~cm}^{-1}$. These peaks were attributed to $\mathrm{C}=\mathrm{O}$ and $\mathrm{C}=\mathrm{C}$ respectively. Similarly, the functional group of $\mathrm{C} \equiv \mathrm{C}$ vibrations are used for quantification analysis and the relative area shows much lesser degradation than the mineral oil. The corresponding peak area and quantification results are shown in Fig. 10.

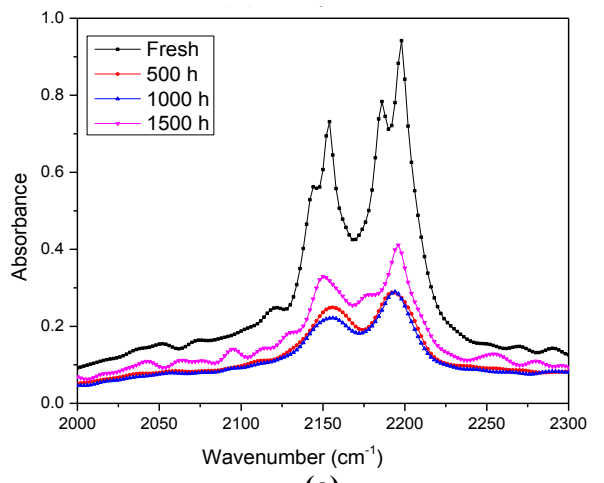

(a)

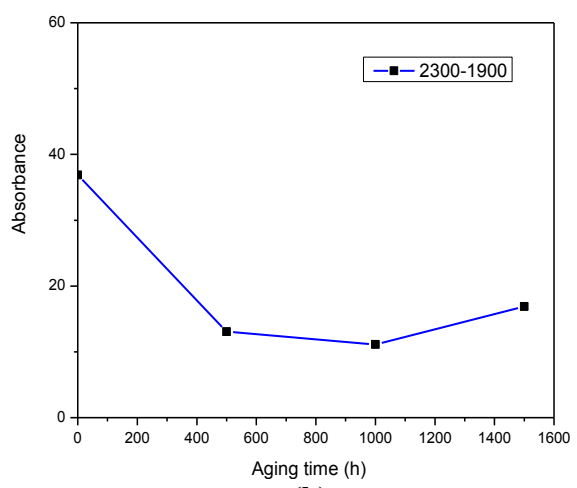

(b)

Fig. 10. (a) FTIR peak position at $2200 \mathrm{~cm}^{-1}$ and (b) Corresponding relative peak area of cellulose paper aged in SE

\section{Conclusion}

FTIR spectra of fresh and aged samples of mineral oil and synthetic ester are studied at different aging durations at $115^{\circ} \mathrm{C}$. The spectrum of mineral oil showed distinctive peaks positions of its internal chemical structures at $\mathrm{CH}_{2}$ and $\mathrm{CH}_{3}$ vibrations. The corresponding quantification analysis confirmed very small reduction in its peak area. Similarly, synthetic ester displayed the important $\mathrm{C}=\mathrm{O}$ vibrations. Chemical stability of synthetic esters under different aging times confirmed the strong surface property of synthetic ester by relative area quantification. Compared to the surface interaction of mineral oil with Kraft paper under different aging conditions, synthetic ester showed significant stability in its chemical structure. This could be due to its internal chemical structure and and the presence of $\mathrm{C}=\mathrm{O}$ group on its structure.

\section{References}

[1] Fofana, I.: 50 years in the development of insulating liquids, IEEE Electr. Insu. Mag., Vol. 29 , No. 5, pp. 13-25, 2013.

[2] Fernandez, I., Ortiz, A., Delgado, F., Renedo, C., Perez, S.,: Comparative evaluation of alternative fluids for power transformers, Electr. Pow. Sys. Res., Elsevier, vol. 98, pp. 5869,2013

[3] Hamdi, A., Fofana, I., Mahi, D.: Stability of mineral oil and oil-ester mixtures under thermal ageing and electrical discharges, IET Gener. Trans. Distrib., Vol. 11, No. 9, pp. 23842392, 2017.

[4] Mohan Rao, U., Sood, Y. R., Jarial, R. K.: Oxidation stability enhancement of a blend of mineral and synthetic ester oils, IEEE Electr. Insul. Mag., Vol. 32, No. 2, pp. 43-47, 2016. 
[5] ASTM D117-18, Standard Guide for Sampling, Test Methods, and Specifications for Electrical Insulating Liquids, ASTM International, West Conshohocken, PA, 2018.

[6] Abdelmalik, A. A.: Analysis of thermally aged insulation paper in a natural ester-based dielectric fluid, IEEE Trans. on Dielectr. Electr. Insul., Vol. 22, No. 5, pp: 2408-2414, 2015.

[7] Tokunaga, J., Koide, H., Mohami, K., Hikosaka, T.: Comparative studies on the aging of thermally upgraded paper insulation in palm fatty acid ester, mineral oil and natural ester, IEEE Trans. on Dielectr. Electr. Insul., Vol. 23, No.1, pp: 258-265, 2016.

[8] Fofana, I., Bouaicha, A., Farzaneh, M.: Characterization of aging transformer oilpressboard insulation using some modern diagnostic techniques, Euro. Trans. Electr. Power, No. 21, pp.1110-1127, 2011

[9] Munajad, A. Subroto, C., Suwarno, S.: Fourier Transform Infrared (FTIR) Spectroscopy Analysis of Transformer Paper in Mineral Oil-Paper Composite Insulation under Accelerated Thermal Aging, Energies, No. 11,364, pp. 1-12, 2018

[10] Bandara, K., Ekanayake, C., Saha, T. K., Annamalai, P. K.: Understanding the aging aspects of natural ester based insulation liquid in power transformer, IEEE Trans. Dielectr. Electr. Insul., Vol. 23, No. 1, pp. 246-257, 2016.

[11] Mohan Rao, U., Pulluri, H., Kumar, N. G.: Performance analysis of transformer oil/paper insulation with ester and mixed dielectric fluids, IEEE Trans. Dielectr. Electr. Insul., Vol. 25, No. 5, pp. 1853 - 1862, 2018. 